\title{
IMAGENS DIGITAIS APLICADAS NO ESTUDO DA ANÁLISE MULTITEMPORAL DO USO E OCUPAÇÃO DO SOLO NUMA MICROBACIA
}

\author{
Sérgio Campos ${ }^{1}$
}

\author{
Talita Teixeira Gobbi ${ }^{2}$
}

Aline Minarelli Reche ${ }^{3}$

RESUMO: O conhecimento da ocupação do solo quanto à sua natureza, localização, forma de ocorrência, mudanças ocorridas em determinados períodos, são de grande valia para a programação de atividades que visam ao desenvolvimento agrícola, econômico e social da região. Este trabalho objetivou identificar e quantificar a ocupação de solo da Microbacia do Córrego Petiço - Botucatu (SP), através do Sistema de Informações Geográficas IDRISI e dados do sensor Landsat 5 TM de 09/06/97 e 23/08/2013. Os resultados constataram-se que a cultura de eucalipto, devido a existência de grandes empresas reflorestadoras na microbacia, juntamente com as florestas são predominantes na área de estudo, o restante da área é ocupada por pastagens e solo preparado para o plantio de culturas agrícolas.

Palavras-Chave: ocupação,solo, culturas, reflorestamento.

\section{DIGITAL IMAGES APPLIED IN THE STUDY OF MULTITEMPORAL ANALYSIS USE AND OCCUPATION OF SOIL IN A WATERSHED}

ABSTRACT: The knowledge of the soil occupation as for his nature, location, occurrence form, changes happened in certain periods, they are valuable for the programming of activities that you seek to the development agricultural, economical and social of the area. This work aimed at to identify and to quantify the soil occupation of Stream Petiço Watershed - Botucatu (SP), through the Geographical

\footnotetext{
${ }^{1}$ Prof. Titular, Departamento de Engenharia Rural, Faculdade de Ciências Agronômicas/UNESP. seca@fca.unesp.br

${ }^{2} \mathrm{Eng}^{\circ} \mathrm{Agr}^{\circ}$, Departamento de Engenharia Rural, Faculdade de Ciências Agronômicas/UNESP.

3 Discente do Programa de Pós Graduação em Agronomia - Energia na Agricultura -Faculdade de Ciências Agronômicas (UNESP/FCA).
} 
Information System IDRISI and data of sensor Landsat 5 TM of 09/06/97 and 23/08/2013. For the analysis of the results it was verified that the eucalyptus culture, due to existence of great reforestation companies in the watershed, together with the native forests they are predominant in the study area, the remaining of the area is occupied by pastures and soil prepared for the planting of agricultural cultures.

Keywords: occupation ,soil, cultures, reforestation

\section{IMÁGENES DIGITALES APLICADAS EN EL ESTUDIO DE USO ANÁLISIS MULTITEMPORAL Y OCUPACIÓN DEL SUELO EN UNA CUENCA}

\section{RESUMEN:}

El conocimiento del uso de la tierra en la naturaleza, ubicación, forma deocurrencia, los cambios en ciertos períodos, son muy útiles para la programación de actividades orientadas al desarrollo agrícola, económico y social de la región. Este estudio tuvo como objetivo identificar y cuantificar la Cuenca de la ocupación del suelode Petiço Stream - Botucatu (SP) a través del Sistema de Información GeográficalDRISI y datos del sensor Landsat 5 TM 06/09/97 y 08/23/2013. Los resultadosencontraron que el cultivo de eucalipto, debido a la existencia de grandes empresas de reforestación en la cuenca, junto con los bosques son predominantes en el área de estudio, el resto de la superficie está ocupada por pastos y tierra preparada para la siembra de cultivos.

Palabras-clave: ocupación, el suelo, las plantas, la reforestación.

\section{INTRODUÇÃO}

Durante os últimos anos, devido ao agravamento da crise econômica principalmente no meio rural, urge a necessidade de obter-se informações atualizadas e precisas sobre recursos naturais existentes nas propriedades agrícolas para fins de planejamento e controle das atividades desenvolvidas nas mesmas, tornando-se assim imprescindível para o manejo e gerenciamento dos recursos naturais. (Hummes et al.,1999)

A grande demanda pelos derivados de madeira, como o papel e a celulose, tem acelerado a expansão de áreas para implantação de reflorestamentos, tanto de eucalipto como de pinus. O Estado de São Paulo, possuidor de modernas indústrias de transformação da madeira em celulose, chapas e aglomerados apresentou um 
aumento considerável na área de cultivo, principalmente na sua porção sudoeste. Vale lembrar que nesta região encontram-se grande parte dos solos ocupados por campos sujos e cerrados, solos estes que suportam perfeitamente a eucaliptocultura e os custos de investimentos são menores que em terras mais férteis. Aliado à essas considerações podemos afirmar, que o município de Botucatu continua como um pólo de atração para reflorestamento e implantação de grandes industrias no setor, visto que, possui estradas estaduais de primeira qualidade, água em abundância e mão de obra.(Barros e Cardoso,1997)

O conhecimento do uso do solo em um determinado local propicia um grande volume de informações sobre as ocupações de solo naquele momento, estas informações permitem o planejamento de atividades agrícolas e estruturação de obras, quer por entidades governamentais ou por instituições privadas. Podendo servir também para análises futuras para avaliar expansões de culturas.

As técnicas de classificação de dados de sensoriamento remoto, conjugadas com SIGs, têm-se consolidado como ferramentas primordiais na obtenção e manipulação de informações espaciais e não-espaciais, gerando cartas temáticas como por exemplo a de ocupação de solo.

As cartas temáticas geradas podem ser úteis no planejamento de amostragem de campo, no acompanhamento de propriedades agrícolas e florestais ou na avaliação de impacto ambiental resultante da instalação da agricultura e da silvicultura. No entanto, o usuário deve entender o significado deste ou daquele tratamento digital de imagens orbitais, refletindo sobre o tempo computacional, a complexidade e o nível de estratificação dos temas envolvidos na análise, a facilidade do manuseio de algoritmos e a oportunidade de transmitir conhecimentos, fazendo chegar na comunidade o retorno científico esperado e aplicável. (Assad e Sano, 1998)

Dentro deste contexto, neste trabalho objetivou-se identificar e quantificar a ocupação de solo da Microbacia do Córrego Petiço - Botucatu (SP), através do uso do Sistema de Informações Geográficas IDRISI.

\section{MATERIAIS E MÉTODOS}


Volume 10, Número 2, 2014

Bacias Hidrográficas, Planejamento e Gestão dos Recursos Hídricos

Esta região está localizada no município de Botucatu-SP entre as coordenadas UTM 772,5 Km e 781,5 Km E, e 7.469 e 7.478 Km N ,com uma área de 3.385,2ha.

Os materiais empregados foram: Imagem digital do satélite Landsat 5 - TM, órbita ponto 220/076 quadrante A, passagem de 09/06/97 e 23/08/2013, adquirida junto ao Instituo de Pesquisas Espaciais (INPE) - São José dos Campos - SP, em CD-ROM e carta topográfica de Botucatu (folha SF-22-R-IV-3) em escala 1:50.000.

O clima da microbacia, segundo a classificação de Köppen, tipo Cfa, com clima temperado chuvoso e com a direção dos ventos predominantes Sudeste/Noroeste (SE/NW). De acordo com Martins (1989), a temperatura média anual na região é de $20,2{ }^{\circ} \mathrm{C}$, sendo as temperaturas médias dos meses mais quentes de $23,2^{\circ} \mathrm{C}$ e dos meses mais frios de $16,9^{\circ} \mathrm{C}$.

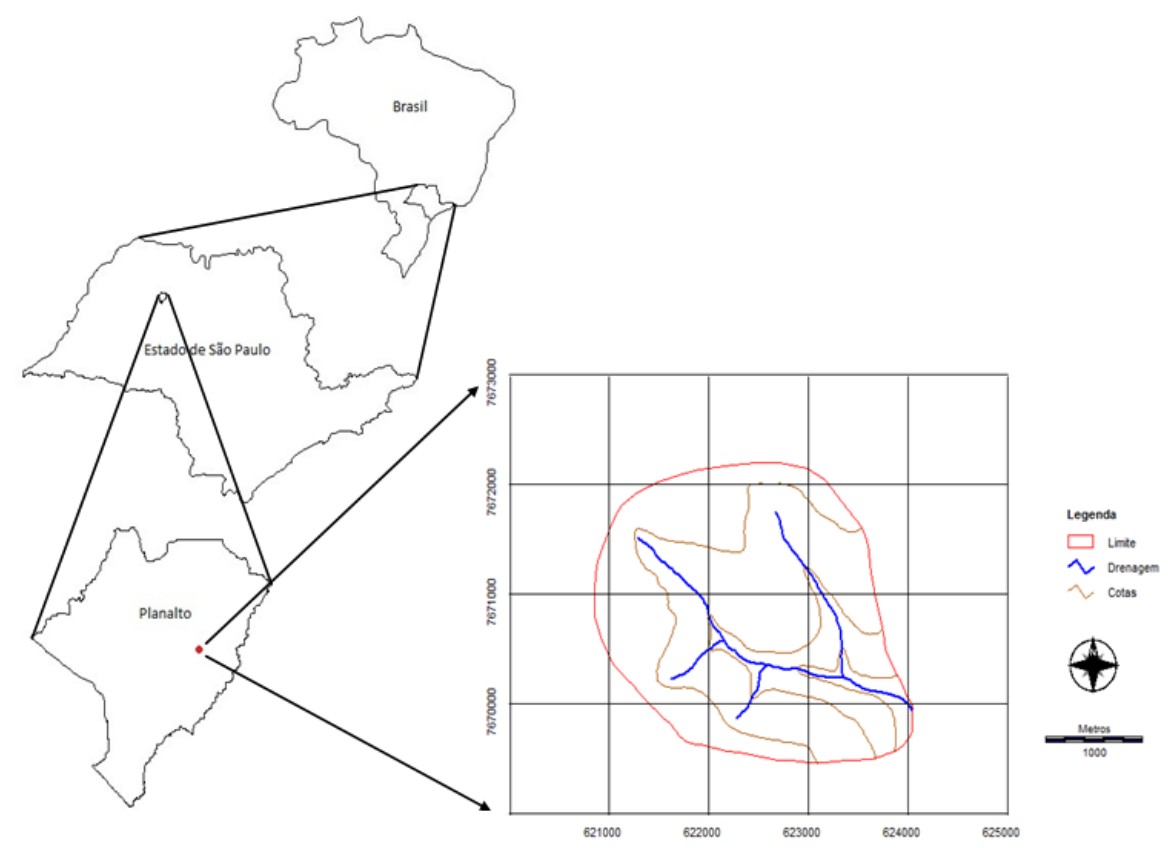

Figura 1: Localização da microbacia do Córrego do Bebedouro, Planalto-SP.

A precipitação média anual é de $1.447 \mathrm{~mm}$, ocorrendo uma precipitação média nos meses mais chuvosos de $223,4 \mathrm{~mm}$ e no mês mais seco de $37,8 \mathrm{~mm}$. As temperaturas máximas absolutas não assumem valores excessivamente altos, privilegiando a região com verão ameno. 
Os Solos do Município (Piroli, 2002) são derivados do arenito e do basalto, com o predomínio dos arenitos. Os principais são:

- Neossolos Quartzarênicos (RQ): são solos de baixa fertilidade com baixa capacidade de retenção de água, são derivados do arenito Botucatu, são muito susceptíveis à erosão e localizam-se ao norte do Município. A sua ocupação atual tem predominância de pastagens e de reflorestamento com eucalipto. Nessas áreas a ocorrência de voçorocas é freqüente.

- Latossolos Vermelho-Amarelos (LVA): são solos profundos de textura leve, bem drenados, com fertilidade baixa e alta suscetibilidade à erosão. No Município aparecem em ampla faixa ao sul, pequena faixa ao norte da parte frontal da "Cuesta"; ocorrem em áreas de relevo suave a ondulado e a cobertura vegetal tem predominância de campo e cerrado. A ocupação atual é composta predominantemente por eucaliptos, pastagens e frutíferas diversas.

- Neossolos Litólicos (RL): apresentam textura argilosa, ocorrem em relevo montanhoso, são solos pouco desenvolvidos e, no Município, aparecem em toda a extensão da "Cuesta". A profundidade é mínima, com vertentes dos vales muito íngremes e de forma convexa. A vegetação nativa tem predominância da fisionomia latifoliada tropical. São solos com abundantes afloramentos de rochas e pouco adequados para agricultura.

- Latossolos Vermelhos (LV): com textura argilosa, são solos profundos, bem drenados, formados a partir de rochas basálticas. No Município, aparecem ao longo da Bacia do Rio Pardo e Rio Lavapés. A vegetação original é de Mata Atlântica, da qual restam pequenos fragmentos. São solos adequados para a cultura do café e culturas anuais (feijão, milho, olerícolas e pastagens).

Como fonte de dados foi utilizada a imagem de satélite nas bandas 3 , 4 e 5 , correspondentes às regiões do espectro visível, do infravermelho próximo e médio do Sensor TM, do LANDSAT 5, órbita 220, ponto 76, quadrante A, passagem de 9 de junho de 1997 e 23 de outubro de 2006, para elaboração da carta de uso da terra do Município de Botucatu. O Sistema de Informações Geográficas - IDRISI Selva foi usado para as análises, sendo a coleta e a confirmação das coordenadas dos pontos de controle a campo realizada por um GPS de Navegação Garmin XL 45. 
Inicialmente, uma composição falsa cor foi elaborada com a combinação das bandas 3, 4 e 5, nas cores azul, verde e vermelho, respectivamente, pois esta apresenta uma boa discriminação visual dos alvos, possibilitando a identificação dos padrões de uso da terra de maneira lógica. Esta composição apresenta os corpos d'água em tons azulados, as florestas e outras formas de vegetações em tons esverdeados e os solos expostos em tons avermelhados.

O georreferenciamento da composição falsa cor foi realizado através do módulo Reformat/Resample do SIG - IDRISI. Os pontos de controle para o georreferenciamento foram obtidos nas cartas topográficas e confirmados "in loco" no campo com o GPS. Após o georreferenciamento, foi feito o recorte da área e demarcadas as áreas de treinamento sobre a imagem com o cursor e o mouse em vários locais, procurando-se abranger todas as variações de cada ocupação do solo.

Para o georreferenciamento das imagens digitais, utilizaram-se dois arquivos de pontos de controle. O primeiro foi criado usando a imagem digital e o outro, a carta topográfica. Os pontos de controle foram escolhidos de forma que cada um deles fosse facilmente identificado, tanto na imagem digital, como na carta topográfica. Foram determinadas as coordenadas de cada ponto e com estes dados foi feito um arquivo de correspondência, sendo colocado inicialmente as antigas coordenadas (carta topográfica) e em seguida, as novas coordenadas (imagem) para cada ponto escolhido, através do comando Edit do menu Database Query, presente no módulo Analysis. Para escolher a equação de melhor ajuste entre os dois sistemas de referência foi utilizado o menu Resample do módulo Reformat, o qual faz a reamostragem e a correção geométrica dos pontos de controle.

Em seguida, foram criadas as assinaturas pelo módulo Makesig e depois, a classificação supervisionada propriamente dita pelo método de Máxima Verossimilhança, através do módulo Maxlike.

Na classificação supervisionada, as classes de uso da terra foram identificadas e diferenciadas em 4 classes de usos das terras representadas por eucalipto, floresta nativa, pastagem e solo exposto. Nesta fase usaram-se seus padrões de resposta espectral. As áreas de treinamento foram delimitadas por polígonos desenhados sobre cada classe de uso da terra na imagem. Em seguida, foram indicadas as assinaturas para cada classe de uso da terra, criando-se um arquivo 
de assinaturas para todas as categorias. A imagem foi classificada com base nesses dados e as amostras de usos das terras duvidosas foram confirmadas a campo com uso do GPS.

A verificação do resultado da classificação foi avaliado estatisticamente através do Índice Kappa. O procedimento sugerido por Eastmann (1999) e por Simões (2001), inicialmente consistiu na geração de pontos aleatoriamente estratificados. O uso da terra no píxel referente à cada ponto foi identificado, sendo criado a seguir um arquivo de valores relacionado aos pontos amostrais da verdade terrestre. Estes dois arquivos foram associados e em seguida rasterizados, gerando uma imagem raster com a verdade terrestre. A seguir, através do módulo Ermat analisou-se estatisticamente a classificação supervisionada confrontando-a com a imagem contendo a verdade terrestre com a imagem classificada do uso da terra. $O$ resultado desta confrontação é uma matriz de erros e o Índice Kappa geral e por categoria.

As áreas dos usos das terras foram determinadas utilizando o comando Area do menu Database Query, pertencente ao módulo Analysis.

\section{RESULTADOS E DISCUSSÃO}

A classificação digital supervisionada (Figuras 2 e 3), obtido da imagem de satélite do LANDSAT em 1997 e 2013, respectivamente, permitiram constatar a existência de 6 classes de uso representativas: Eucalipto, floresta, pastagens, várzea e represa.

O uso da terra (Tabela 1) indica que aproximadamente $3 / 5$ da área de estudo era coberta por pastagens em 1997, comprovando a vocação da região para a pecuária (Campos, 1993).

A cobertura florestal, representada por florestas predominou em 29,24\% (1997) da área. Essas florestas são formadas por vegetações arbóreas, ou seja, matas ciliares, cerrados e florestas propriamente ditas. Segundo o Código Florestal (1965) a reserva mínima de florestas deve ser de 20\%. Assim, nota-se que não há deficiencia de florestamento. 

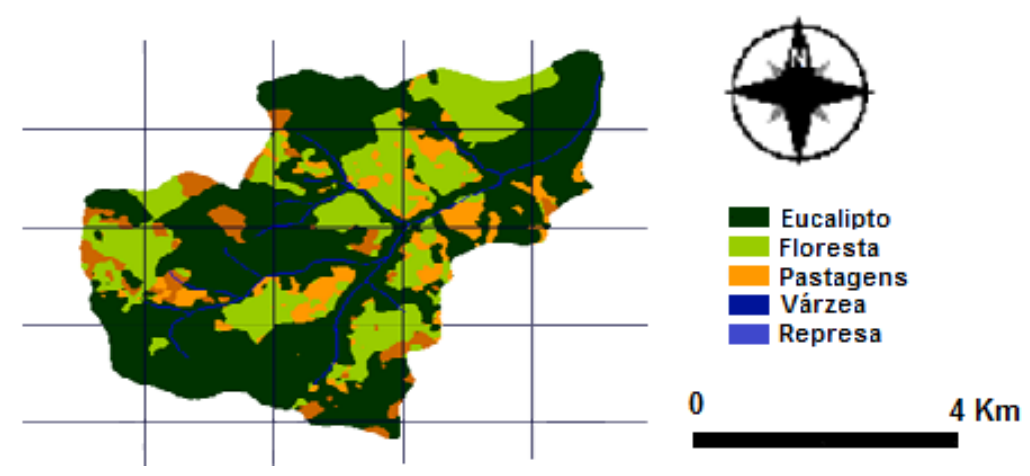

Figura 2. Ocupação do Solo da Microbacia do Córrego Petiço - Botucatu (SP) em 1997.

As florestas ocorrentes na área de estudo são, em sua grande maioria, representadas por matas ciliares. Isto permite inferir que não houve intervenção humana nestes locais devido à proteção dada pela Legislação Florestal vigente, pois o Código Florestal define essas áreas situadas às margens de cursos d' água, rios e ao redor de nascentes como sendo áreas de preservação permanente.

Os reflorestamentos por eucalipto em 2013, outra cobertura florestal significativa na microbacia ocorreram em 43,70\% da área. Estes apresentam grande importância econômica, fornecendo matéria-prima para as indústrias de beneficiamento de madeiras e de produtos derivados, como chapas de fibra, aglomerados e compensados. Esse uso da terra e as atividades derivadas vêm gerando muitos empregos e contribuindo para o desenvolvimento econômico e social dos municípios da região. O reflorestamento, além de ser eficiente na proteção da rede de drenagem em regiões com processos erosivos (Cardoso, 1988), tem grande influência no mecanismo hidrológico, retardando e desviando o escoamento superficial e conseqüentemente o processo erosivo (Vieira, 1978), além de atender às necessidades econômicas na substituição das derrubadas das matas naturais que não são impedidas e cuja regeneração é lenta.

O reflorestamento por eucalipto apresenta grande tendência de evolução na área de estudo, visto que encontram-se instaladas duas empresas de grande porte quais sejam Duratex e Eucatex, além de outras que utilizam áreas do município para o cultivo de reflorestamento. Com o crescimento desse setor e o aumento da procura pelos produtos produzidos por estas empresas, torna-se necessário à 
expansão das áreas de reflorestamento, pois devido a proximidade às empresas, torna a expansão interessante pela redução de custos em tarifas de transporte, devido as menores distâncias percorridas da floresta a empresa, bem como pelas por vias de acesso em boas condições de tráfego, reduzindo os custos com manutenção de veículos, tornando a região atrativa a novos investimentos.

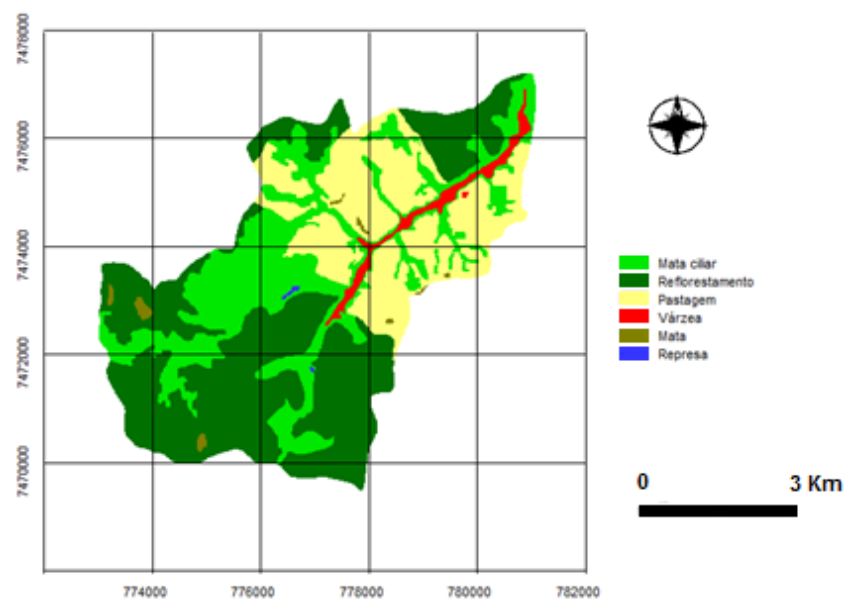

Figura 3. Ocupação do Solo da Microbacia do Córrego Petiço - Botucatu (SP) em 2013.

Tabela 1. Ocupações do solo na Microbacia do Córrego Petiço Botucatu(SP), no período de 1997 a 2013.

\begin{tabular}{|c|c|c|c|c|c|}
\hline \multirow{3}{*}{ Uso da Terra } & \multicolumn{4}{|c|}{ Área e \% de ocupação } & \multirow{3}{*}{$\begin{array}{l}\text { \% de redução } \\
(\mathrm{R}) \text { ou } \\
\text { ampliação }(A)\end{array}$} \\
\hline & \multicolumn{2}{|c|}{1997} & \multicolumn{2}{|c|}{2013} & \\
\hline & ha & $\%$ & ha & $\%$ & \\
\hline Reflorestamento & 1993,16 & 58,88 & 1479,22 & 43,70 & $15,18(R)$ \\
\hline Florestas nativas & 786,49 & 23,23 & 989,98 & 29,24 & $6,01(\mathrm{~A})$ \\
\hline Pastagens & 523,59 & 15,47 & 831,42 & 24,56 & $9,09(\mathrm{~A})$ \\
\hline Várzea & 78,621 & 2,32 & 81,13 & 2,40 & $0,08(\mathrm{R})$ \\
\hline Represa & 3,34 & 0,10 & 3,45 & 0,10 & - \\
\hline Total & 3385,20 & 100 & 3385,20 & 100 & \\
\hline
\end{tabular}

A cobertura vegetal vem sofrendo modificações constantes com a ação do ser humano, sendo mais intensa essa dinâmica nos solos com melhor fertilidade e de 
condições ecológicas mais propícias para a exploração agrícola. Contudo, com o aumento da densidade demográfica e o aperfeiçoamento das técnicas agronômicas, os solos mais pobres também vêm sendo utilizados para atividades agropecuárias.

Este fato já está ocorrendo na região de Botucatu, onde áreas ocupadas, em épocas remotas com matas, foram ocupadas por pastagens e reflorestamentos, de rápido retorno econômico para o produtor rural, como é o caso da cana-de-açúcar e mais recentemente por citros.

A ocupação do solo no período permitiu inferir que as pastagens que ocupavam quase $16 \%$ em 1997, sofreram uma ampliação, passando a ocupar quase 25\%, em 2013, mostrando a importância da pecuária na região. Essa ampliação vem acontecendo por causa da redução dos reflorestamentos. As pastagens, mesmo sendo mal conduzidas, é uma cultura significativa na região, pois a pecuária bovina de leite tem uma certa predominância na região. De maneira geral, a pecuária na região é desenvolvida de forma extensiva com pastagens de baixa produtividade, pois os produtores não costumam efetuar correções de $\mathrm{pH}$ e adubação de manutenção nessa cobertura vegetal para melhorar a qualidade desse alimento animal. Como a conservação do solo é uma prática agronômica mal utilizada pelos pecuaristas, os solos, que, por natureza, são pobres, acabam sofrendo com a ação das intempéries, acarretando em assoreamentos do Alto Rio Pardo - Botucatu (SP), a diminuição da capacidade de suporte da vegetação para o gado, e a conseqüente queda da produção leiteira.

As florestas, muito importantes em termos de preservação ambiental (Rocha, 1991), são fundamentais no controle de erosão e de enchentes, pois quando estão situadas em locais adequados são fundamentais na recarga do lençol freático. Essa classe de uso, composta por florestas primárias e secundárias e matas de galeria (matas ciliares), de maneira geral, ocorrem em pequenas áreas por toda a extensão do município, porém, com maior concentração nas áreas com relevo acentuado, onde as condições para mecanização são dificultadas porque o acesso é difícil.

As florestas ocorrentes na área de estudo, permitiu inferir que houve intervenção humana nestes locais, com exceção das áreas protegidas pela Legislação Florestal vigente, pois o Código Florestal define essas áreas situadas às margens de cursos d' água, rios e ao redor de nascentes como sendo áreas de 
preservação permanente. O mesmo Código determina serem áreas protegidas, todos aqueles locais de alta declividade. De acordo com Barros (1988) e Campos (1993), a topografia também é um fator limitante à ocupação das terras da região, pois as altas declividades dificultam ou impedem a mecanização, o que contribui para a manutenção da cobertura florestal nestas áreas, pois os desmatamentos agridem o solo, deixando-o descoberto e sob a ação das chuvas, aparecendo, em conseqüência, as erosões e a lixiviação dos elementos nutritivos essenciais para a sobrevivência das plantas. Desta maneira, o uso do solo deve se realizado de forma racional, adequado e não agressivo ao meio ambiente.

As imagens de satélites têm condições de oferecer uma visão clara, abrangente e atual do uso da terra. A discriminação, o mapeamento e a quantificação das áreas de uso da terra através da classificação supervisionada pelo Sistema de Informações Geográficas permitiu obter resultados com maior agilidade quanto á integração e manipulação das áreas.

A avaliação da exatidão para a classificação supervisionada realizada pelo índice Kappa foi de 0,43, cuja qualidade foi classificada como boa, segundo Landis e Koch (1977). Como foi possível analisar somente 6 classes de uso, pode-se concluir que é necessário a aplicação de uma classificação supervisionada mais rigorosa para mapeamentos futuros nessa área.

\section{CONCLUSÃO}

Os resultados obtidos com a metodologia utilizada permitiram concluir que as imagens do sensor Thematic Mapper do Landsat 5 TM forneceram uma boa base de dados para a classificação digital da ocupação do solo e o Sistema de Informação Geográfica Idrisi permitiu determinar a ocupação do solo da microbacia de maneira rápida; pois as informações geradas por este trabalho poderão servir de fonte para novos estudos, planejamentos de novas atividades relacionadas a ocupação do solo e também para reavaliações da ocupação atual; bem como as análises mostram que a área tem predominância de atividades tecnificadas e rentáveis economicamente, 
devido vantagens ambientais, topográficas e geográficas tornando-a atrativa à novos investimentos.

\section{REFERÊNCIAS}

Assad, E. D. e Sano, E. E. - Sistema de Informações Geográficas aplicações na agricultura $2^{\text {a }}$.ed. ver. E ampl. - Brasília/DF - Embrapa - SPI/ Embrapa - CPAC, 1998. 434p.

BARROS, Z.X. de Caracterização de bacias hidrográficas no mapeamento de solos mediante o uso de análise multivariada. Botucatu: UNESP, 1988. 113p. Tese (Doutorado em Energia na Agricultura) - Faculdade de Ciências Agronômicas, Universidade Estadual Paulista "Júlio de Mesquita Filho", 1988.

CAMPOS, S. Fotointerpretação da ocupação do solo e suas influências sobre a rede de drenagem da bacia do rio Capivara - Botucatu (SP), no período de 1962 a 1977. Botucatu: UNESP, 1993. 164p. Tese (Doutorado em Energia na Agricultura) - Faculdade de Ciências Agronômicas, Universidade Estadual Paulista, 1993.

CARDOSO, L.G. Comportamento das redes de drenagem em solos com cana-de-açúcar e com eucalipto. Botucatu: UNESP, 1988. 139 p. Tese (Doutorado em Energia na Agricultura) - Faculdade de Ciências Agronômicas, Universidade Estadual Paulista, 1988.

EASTMAN, J. R. Guide to GIS and image processing. Massachusettes, Clark University. V. 2, 1999. 169p.

LANDIS, J.R., KOCH, G.G. The measurement of observer agreement for categorical data. Biometrics, v. 33, n.1, p. $159-174,1977$.

MARTINS, D. Clima da região de Botucatu. In: ENCONTRO DE ESTUDOS SOBRE A AGROPECUÁRIA NA REGIÃO DE BOTUCATU, 1, 1989, Botucatu. Anais... Botucatu, UNESP, 1989, p.08-19.

PIROLI, E.L. Geoprocessamento na determinação da capacidade e avaliação do uso da terra do município de Botucatu-SP. 2002. 108f. Tese (Doutorado em Agronomia/Energia na Agricultura) Faculdade de Ciências Agronômicas, Universidade Estadual Paulista, Botucatu, 2002.

ROCHA, J.S. M. da., Manual de manejo integrado de bacias hidrográficas. ed. UFSM, Santa Maria, RS. 1991. 181p.

SIMÕES, L.B. Integração entre um modelo de simulação hidrológica e Sistema de Informação Geográfica na delimitação de zonas tampão ripárias. Botucatu, 2001.171p. Tese (Doutorado), Faculdade de Ciências Agronômicas, Universidade Estadual Paulista, 2001.

VIEIRA, N.M. Estudo geomorfológico das voçorocas de Franca, SP. Franca: UNESP, 1978. 255p. Tese (Doutorado em História) - Instituto de História e Serviço Social, Universidade Estadual Paulista, 1978. 